\title{
Orientations to negotiated language and task rules in online L2 interaction
}

\author{
OLCAY SERT \\ Hacettepe University, Turkey \\ (email: osert@hacettepe.edu.tr) \\ UFUK BALAMAN \\ Hacettepe University, Turkey \\ (email:ubalaman@hacettepe.edu.tr)
}

\begin{abstract}
Recent research shows that negotiation of meaning in online task-oriented interactions can be a catalyst for L2 (second/foreign/additional language) development. However, how learners undertake such negotiation work and what kind of an impact it has on interactional development in an L2 are still largely unknown mainly due to a lack of focus on task engagement processes. A conversation analytic investigation into negotiation of meaning (NoM) in task-oriented interactions can bring evidence to such development, as conversation analysis (CA), given its analytic tools, allows us to see how participant orientations in interaction evolve over time. Based on an examination of screen-recorded multiparty online task-oriented interactions, this study aimed to describe how users $(n=8)$ of an L2 (1) negotiate and co-construct language and task rules and (2) later show orientations to these rules both in the short term (50 minutes) and in the long term ( 8 weeks). The findings showed that in addition to negotiating existing rules, the learners co-constructed new rules around an action called policing, which occurred when the learners attended to the breach of language and task rules. Furthermore, even after the negotiation work was completed, they oriented to negotiated rules through policing their own utterances (i.e. self-policing). Overall, this interactional continuum (from other-repairs to self-repairs) brought longitudinal evidence to bear on the role of NoM in the development of L2 interactional competence. These findings bring new insights into NoM, technologymediated task-based language teaching (TBLT), and CA for second language acquisition (SLA).
\end{abstract}

Keywords: negotiation of meaning, task-based, online interaction, conversation analysis

\section{Introduction}

Interactional competencies used and developed by L2 (second/foreign/additional language) users (Pekarek Doehler \& Pochon-Berger, 2015) in online settings have significant potential to contribute to second language acquisition (SLA) and task-based language teaching (TBLT) and learning. Studies revealing the learning potential of online L2 tasks have generally been carried out following cognitivist/interactionist (e.g. Doughty \& Long, 2003) and sociocultural-theory-informed agendas (e.g. Belz \& Thorne, 2006). Having dominated 
the fields of SLA and computer-assisted language learning (CALL), the interactionist approach to TBLT has relied on the mapping of form-function relations and reducing them into constructs (e.g. recasts, uptake), which then can be correlated with pre-given contextual features (e.g. settings and participants). Quantitative descriptions of these constructs and categories, however, are not "designed to take into account the interpretive actions of parties involved in L2 use" (Lee, 2013: 863).

This limitation can be overcome by adopting conversation analysis (CA) methodology. CA enables ways for looking into how L2 users show their understanding of a previous utterance in interaction, and how their turn shapes the understanding of listeners. This is a level of descriptive adequacy (Lee, 2013) required to make analytic claims, and the sequential approach inherent in CA can thus be conducive to revealing social actions in online L2 task-oriented interaction. A micro-analytic investigation can also reveal learning opportunities in these settings by explicating the interactional and multimodal resources (e.g. gestures, orientations to task interface, and on-screen tools) employed by learners.

Motivated by the methodological potential of CA, this study documents L2 (i.e. English language) learners' changing interactional practices and explores their task-oriented interactions in weekly online meetings. During these meetings, the learners try to complete tasks without the presence of a teacher or a moderator. The main research focus is on the instances of negotiation of meaning (NoM) in repair sequences that commonly include an action called policing (cf. Amir \& Musk, 2013). Policing can be broadly defined as interactants' attempts to maintain normative preferences when there is a deviation from a norm (e.g. choice of Turkish vs. English). The paper illustrates the policing action within a continuum that starts with other-repairs (i.e. when the listener polices), which over time evolve into self-repairs (Martin, 2004, 2009; Martin \& Sahlström, 2010). We frame this evolution and change across time as part of the development of L2 interactional competence (Hall \& Pekarek Doehler, 2011), thus learning (Martin, 2009). Consequently, the present study extends the scope of NoM for SLA by bringing developmental evidence on the basis of L2 learners' policing practices within repair sequences. To further explicate the conceptual background to this study, the following sections include a review of (1) NoM in online L2 task-oriented interactions, and (2) conversation analytic approach to L2 interaction data. Following the literature review, the methodology section presents descriptions of the participants, task design, and the analysis of the data. We then analyse the extracts and conclude the paper with a discussion.

\section{Literature review}

\subsection{Negotiation of meaning in online L2 task-oriented interactions}

Negotiation of meaning informed by the interaction hypothesis (Long, 1996) in SLA is defined as a cognitive process that occurs when interactants attend to communication breakdowns in order to repair and understand one another (Jepson, 2005; Nakahama, Tyler \& Van Lier, 2001; Varonis \& Gass, 1985). These negotiations are "a series of conversational turns" (van der Zwaard \& Bannink, 2014: 138) starting with "explicit indication of nonunderstanding" (Smith, 2005: 44). They are then followed by a response, and finally an optional reaction to the response as formulated in Varonis and Gass's (1985) stepwise 
discourse model: trigger, indication, and response (resolution), and reaction to response (optional). The negotiation work undertaken while following these steps has been considered valuable for facilitating L2 acquisition (Long, 1996), which can also be extended to L2 pedagogy through the implementation of TBLT procedures.

TBLT researchers have investigated the impact of various task types (e.g. information gap and jigsaw tasks) on NoM. Nakahama et al. (2001) found that whereas information gap tasks trigger more repair work, learners formulate more complex utterances within conversational activities. They also assert that communication breakdowns help learners notice a gap in their L2 since they negotiate to repair these breakdowns, which is a process also known as interactional modifications, potentially enhancing L2 acquisition (Long, 1996; Zheng, Young, Wagner \& Brewer, 2009). Foster and Ohta (2005), on the other hand, suggest that NoMs occurring during information-exchange task interactions are only one of the many other catalysts for SLA. They also note that self-correction is more common than other-correction, which is also one of the initial findings of early conversation analytic research on repair (i.e. preference for self-repair; Schegloff, Jefferson \& Sacks, 1977).

The preference for self-repair has been examined in terms of NoM (Mori, 2004), especially in online text-based computer-mediated communication environments (Bower \& Kawaguchi, 2011; Jepson, 2005; Lee, 2001; Yüksel \& İnan, 2014). Comparisons of face-toface and text-chat interactions show that NoM in task-oriented text chat differs significantly from NoM in face-to-face interactions (Jepson, 2005; Kern, 1995; Pellettieri, 2000; van der Zwaard \& Bannink, 2014; Yüksel \& İnan, 2014). It has even been suggested that NoM in text chat is superior to face-to-face interaction in that it (1) allows learners to negotiate meaning at their own pace (Fernández-García \& Martínez-Arbelaiz, 2002); (2) helps noticing of L2 forms and meaning (Kitade, 2000; Pellettieri, 2000; Salaberry, 2000; Shekary \& Tahririan, 2006); (3) promotes learning of lexical items (Fernández-García \& Martínez-Arbelaiz, 2002; Smith, 2004, 2009); (4) enhances grammatical competence (Pellettieri, 2000); (5) ensures high level of motivation and positive attitudes (Kitade, 2000; Meunier, 1998); and lastly (6) improves oral production skills (Kitade, 2000) through cross modality (Yanguas, 2010).

The bulk of research on NoM in online environments has been based on text chat. Although these studies have helped create a concrete theoretical background to NoM research in technology-mediated TBLT, they lack an emphasis on other modalities (i.e. audio and video). A few examples that focus on NoM in task-oriented interactions include Yanguas $(2010,2012)$ on audio-chat interaction, and Wang (2006) and van der Zwaard and Bannink $(2014,2016)$ on video-chat interaction. Another common aspect of NoM research in technology-mediated TBLT is the methodology that originated from Varonis and Gass's (1985) model. Some researchers (Fernández-García \& MartínezArbelaiz, 2002; Smith, 2003; Yanguas, 2010) applied the model to code instances of NoM in their data (van der Zwaard \& Bannink, 2014, 2016), and then counted the number of occurrences for further statistical processing in order to compare variables across different modes or task types.

Before we move on with how conversation analysts treat L2 task-oriented interaction data, we will briefly explain the action of policing. Language policing, originating in CA research on code-switching (Auer, 1984; Bonacina-Pugh, 2012; Gafaranga, 2000, 2010), is the implicit (Hazel, 2015) and/or "explicit orientation and attempt to re-establish the 
monolingual policy" (Amir, 2013: 92; Amir \& Musk, 2013). In L2 talk-in-interaction, such an orientation has been observed at micro-level detail in a number of studies, including the ones on teacher-fronted classroom interaction (Sert, 2015). Whether this is seen in an L2 classroom, or, as in our case, in online learner-learner interaction, attending to the norm explicitly and repairing the trouble source facilitates negotiation.

\subsection{A conversation analytic approach to L2 interaction data}

This paper refers to the significant potential of conversation analytic research on online task-oriented interaction, thus on technology-mediated TBLT (Balaman, 2016; Balaman \& Sert, 2017b). Previous research has signaled this potential through micro-detailed descriptions of online interactions (cf. González-Lloret, 2015; Jenks, 2014; Tudini, 2010; Tudini \& Liddicoat, 2017). It has also been embodied in CA-for-SLA's alternative approach to the treatment of SLA data (Firth \& Wagner, 1997; Kasper \& Wagner, 2011; Markee \& Kasper, 2004), which contributed to task-based interaction research (Hellermann, 2008; Hellermann \& Pekarek Doehler, 2010; Markee \& Kunitz, 2013; Mondada \& Pekarek Doehler, 2004; Seedhouse, 2005). An understanding of the methodological orientation in this study requires explaining how $\mathrm{CA}$ and an interactionist SLA approach to task-based interaction differ.

One of the differences between interactionist SLA and a CA approach to task-based interaction is that in the former, interactional moves (e.g. comprehension checks, clarification requests) are coded by researchers (e.g. Sotillo, 2000). Such codes are then transformed into quantifiable data points. Hauser (2005) problematizes coding and its subsequent transformation process inherent in interactionist SLA, claiming that such a process may "obscure what is happening in the interaction and what participants take to be the action or actions achieved by any particular turn" (310). This is not to say that all interactionist SLA studies have inherent methodological problems, but more transparent and holistic criteria are required that satisfy a descriptive adequacy (Lee, 2013). An approach sensitive to sequential context (drawing on next-turn-proof-procedure rather than researcher-attributed functions of individual turns) and participants' analyses of each other's turns (emic perspective rather than an exogenous, etic one) seem to be advantages of a CA approach to task-based online interaction data. Furthermore, CA findings have revealed that multiple actions can be performed by individual turns, which then makes coding of turns very difficult, if not problematic. Lastly, in the analyses of multimodal interaction data that include different layers like screen recordings, the development of a coding scheme for actions cannot be without problems. An approach to data that has been proven useful in unpacking simultaneous modalities (i.e. gestures, screen behaviors, and talk) should be adopted (see also Balaman \& Sert, 2017a), as we set out to do with the current study.

\subsection{The current study}

This paper describes how L2 learners facilitate the emergence of the rules, and repair their teammates (other-repair) and themselves (self-repair) in moments of divergence from the rules (i.e. policing). Furthermore, the developmental data include instances during which the participants orient to the negotiated task rules, which evidences the change over time and 
across interactional practices. We consider NoM exchanges as processes that are talked into being by the interactants' minute-by-minute and turn-by-turn co-construction of meaning to establish intersubjectivity. Therefore, we employ CA methodology (see Section 3, Methodology) and draw on practices such as repair, which is actually the sine qua non of a NoM sequence (Long, 1996; Varonis \& Gass, 1985). Schegloff et al. (1977) define repair "as the set of practices whereby a co-interactant interrupts the ongoing course of action to attend to possible trouble in speaking, hearing or understanding the talk" (as cited in Kitzinger, 2013: 229). This definition seems to align with the NoM definition in the SLA literature (Jepson, 2005; Long, 1996; Nakahama et al., 2001; Varonis \& Gass, 1985), although it is not referred to as a situated accomplishment based on sequential analysis. By treating the online task-oriented interaction data using CA, the current study demonstrates that L2 learners repair their teammates' talk, hence negotiate for the language and task rules around policing action (Amir \& Musk, 2013).

This research also describes a new type of policing (i.e. rule policing). Rule policing occurs when a task rule is breached and negotiated within repair sequences. It is argued that the participants in L2 task-oriented interactions attend and orient to emergent and co-constructed language and task rules, and that they perform NoM within repair sequences. The study also addresses a large research gap in NoM research in terms of video modality in chat environments (also multimodality enriched with screen recordings), which is of utmost importance for an overall understanding of the affordances of online interactional settings. The move from text-based chat to screen-recorded video-based interaction brings in two clear advantages: first, the non-verbal actions including gestures can be incorporated into the analysis; and second, participants' on-screen behaviours can be synchronised with talk and other embodied conduct (Balaman \& Sert, 2017a, b).

Against this background, this study addresses the following research questions:

1. How do the participants negotiate and co-construct language and task rules within the emergent online task-oriented interactions?

2. How are the language and task rules made relevant and oriented to in accomplishing the online tasks?

The next section describes the methodology and the task design in order to present an overview of language and task rules that have been policed, therefore the meaning that has been negotiated.

\section{Methodology}

This section will describe (1) the participants, (2) the online interactional setting and the task interface in relation to task design procedures, and (3) the research methodology. The participants were undergraduate students, aged 18 to 22, in an English language teaching program at a Turkish state university. They were enrolled into the program as high achievers of a language proficiency test, which includes multiple-choice questions on grammar, vocabulary, and reading. There is, however, no concrete evidence for their level in writing, speaking, and listening, as the test does not assess these skills. The students were also members of a leisure-time conversation club, offered complementary to their communication classes, where they regularly met to practice interaction in English with their peers based in the department. 


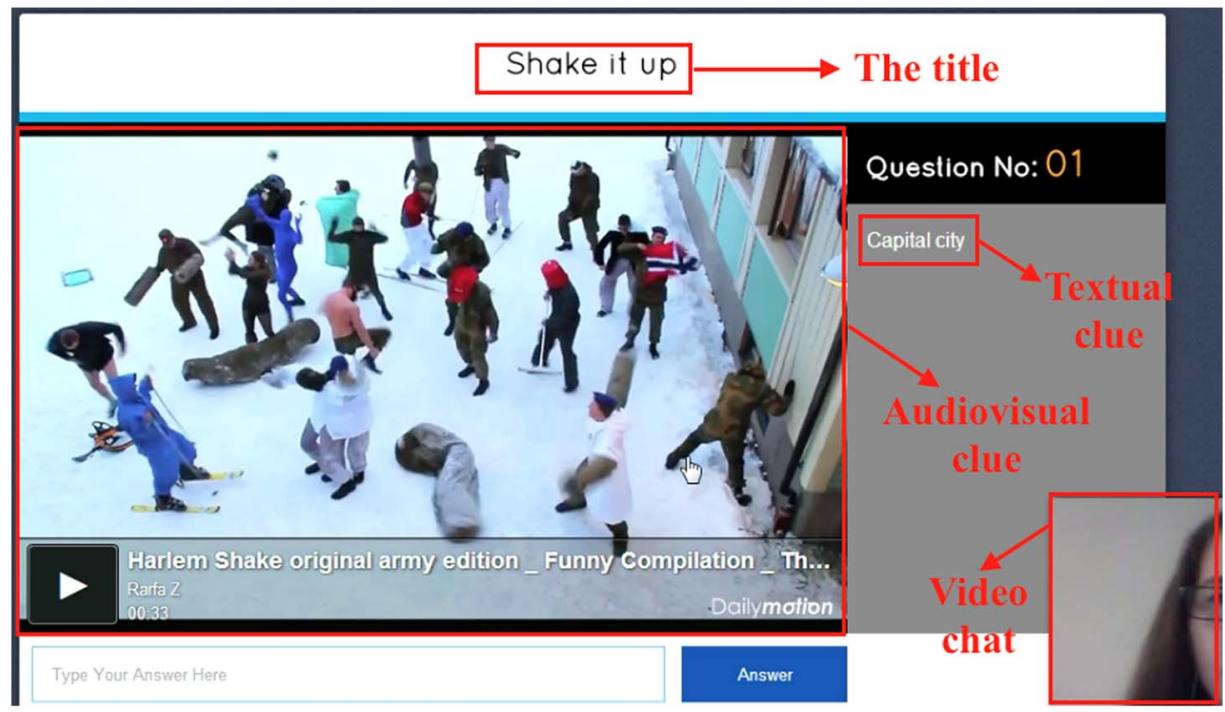

Figure 1. Screenshot of the task interface in Extract 2

The online task environment was designed to provide an alternative medium and activity to the members. We made an open call for participation to the activity and gathered voluntary participants (i.e. 20 participants) for an introduction meeting. Consents were granted so that the data could be used for research purposes. We provided instructions to make sure that participants could (1) use the webpage consisting of three textual and audio-visual clues for each question prepared by the researchers (see Figures 1-4), (2) attend video-chat sessions on Google Hangouts to accomplish the tasks collaboratively, (3) record their own screen activities, and (4) deliver the screen recordings to the researchers. We collected 70 hours of screen-recorded interactions over 18 weeks; however, we focus on only a representative proportion of the corpus. To this end, although there were five teams, each consisting of four participants, we focus on the interactions of two teams (Team 1 and 2) across 8 weeks through four extracts that best represent the findings based on a larger collection (i.e. 16 extracts), which provides the developmental evidence for the participants' orientations to negotiated rules across time. The findings explicate both short-term development (in 50 minutes) and long-term development (in 8 weeks) across two points of time (i.e. one for starting and one for end points) in the data collection process.

For task design purposes, we adopted a different approach and referred to information gaps (Doughty \& Pica, 1986) as dynamic and emergent in nature, and co-constructed in and through interaction (Balaman, 2015, 2016; Jakonen \& Morton, 2015). This view was also reflected in the only predetermined rule of the task, which was do not tell the correct answer to your teammates directly, but start providing clues to help them find it. The view also guided us through the design of the task interface, which did not allow the participants to proceed to the next question until each member of the team found the correct answer. Each week, the participants had to interpret, discuss, and combine the clues to answer a particular keyword for each of the three questions while they also followed the task rule. 
This design procedure facilitated the emergence of the following actions in an ordered fashion:

1. The participants were gathered online on a Google Hangouts chat room and went online on the task website.

2. They coordinated their on-screen activities with video chat on Google Hangouts in order to make sense of the clues (cf. Balaman \& Sert, 2017a) (e.g. Figure 1 aims to lead the participants to a correct answer by implicating Harlem Shake with the title, noticing the flag in the video, and finally finding the capital city of the country whose flag is in the video based on the textual clue).

3. They tried their candidate answers on the task interface, and after one of the participants found the correct answer (i.e. emergence of knowledge gap), that participant was expected to facilitate task completion by providing hints.

All in all, the task environment encouraged multiparty interaction for task accomplishment and created learning opportunities by design. Accordingly, all emergent interactions were context-shaped to some extent to eventually pave the way for task-induced development in an L2. Such development emerged from the dynamic and emergent information gaps driven by the task design (Balaman, 2015) that also facilitated the emergence of new rules such as we can tell wrong answers (Balaman, 2016) and target language only. In this paper, we limit our focus on do not tell the correct answer and target language only rules.

In the analysis of the data, we adopt CA, which is a research methodology that treats social interaction as the central conduct of human life (Sidnell, 2010). CA explicates the ways interactants co-construct meaning through the systematic order of talk-in-interaction (Sacks, Schegloff \& Jefferson, 1974), adopting a participant-relevant (i.e. emic) perspective to the analysis of data. CA focuses on social practices, or so-called members' methods, such as turn-taking, repair, sequence organization, and preference organization (Sidnell \& Stivers, 2013). Therefore, CA findings are strictly based on observable interactional practices that the participants talk into being at turns-at-talk. Following the data collection and transcription processes (see Appendix for transcription conventions), the next step was to conduct an "unmotivated looking" procedure, which is the preliminary examination of data to explore any emergent phenomenon that is made accessible to the researchers (ten Have, 2007). Then, the emergent phenomenon was investigated for recurring patterns across different segments of the data for compiling collections of cases. We should also note that CA findings are completely data-driven and are not informed by any theoretical constructions, hypotheses, or assumptions. They may nevertheless be compared to previous findings in the literature in a post-analytic discussion, which is undertaken in this study particularly in terms of NoM in SLA.

\section{Analysis and findings}

A collection of all cases across the data set shows that the rules unfold within other-initiated other-repairs and self-initiated self-repairs. A close analysis of these repair sequences indicates that the participants constantly negotiate, co-construct, and orient to microlevel policies. The interactants bring the pre-determined task rule into their interaction 
through rule policing (Extracts 1 and 3) and language policing (Extracts 2 and 4) which appears when the participants orient to language rules by attending to the use of first language (L1) (i.e. Turkish) as a rule breach. An interactional continuum starting with the overuse of other-initiated other-policing, which then evolves into self-initiated rule and language policing, is described as the unit of development. Section 4.1 illustrates the ways language and task rules are negotiated and co-constructed in situ by the participants; and Section 4.2 explicates the shift to self-policing practices. Therefore, the study also demonstrates the participants' compliance with the previously co-constructed rules by enacting the rules and displaying preference to interact in English. These changes of practices across time help us understand how these L2 users develop and learn task rules in interaction, while they also negotiate meaning in L2, establishing the use of L2 as the normatively preferred practice.

\subsection{Negotiation and situated co-construction of task rules}

This section brings conversation analytic evidence to the participants' negotiation and co-construction of task rules. The recordings of the first weeks include numerous sequences of other-policing as is showcased by the two extracts in this section. Extract 1 from the second week of the data collection process presents how the predetermined task rule emerges in situ as the participants are trying to find the correct answer (second) based on the clues exhibited in Figure 2. The policing action is performed overtly when the participants negotiate the task rule using an other-initiated other-repair. Prior to the extract, NUR and SIN find the correct answer and start providing clues in order to help their teammates find the correct answer (see Appendix for transcription conventions).

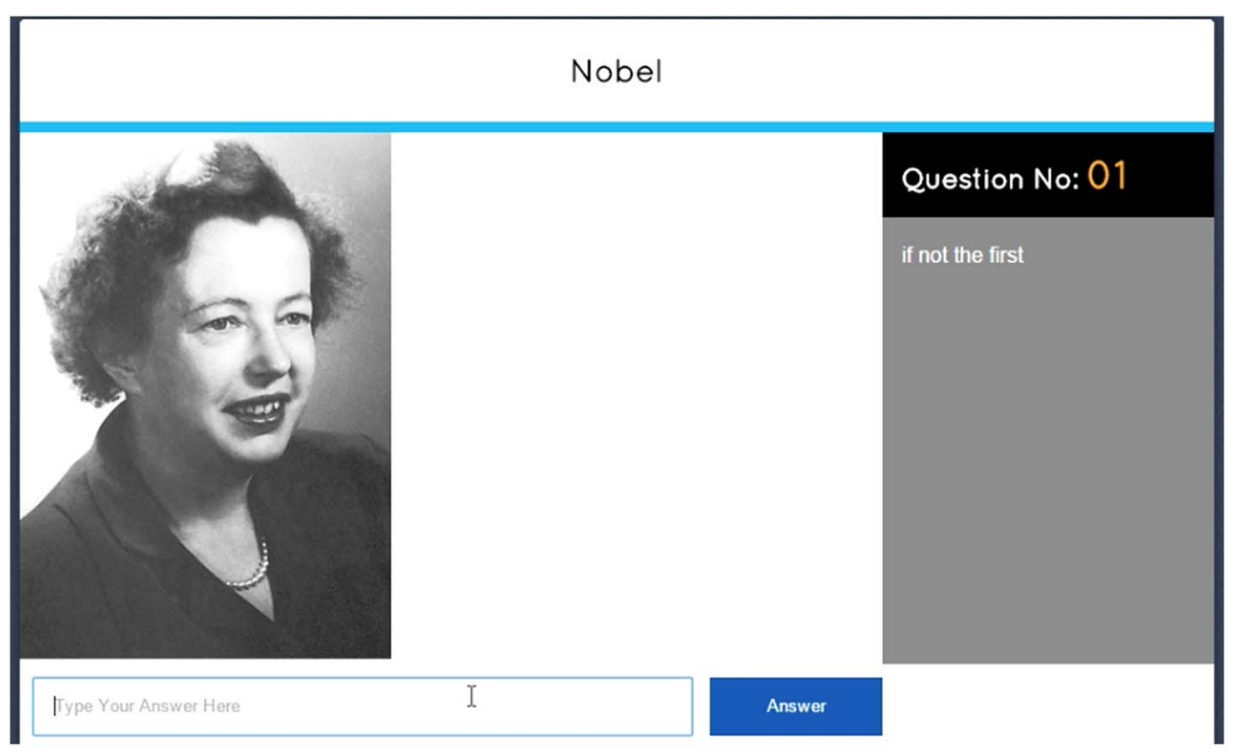

Figure 2. Screenshot of the task interface in Extract 1 
Extract 1. Other-initiated other (rule) policing; Team 1 Week 2

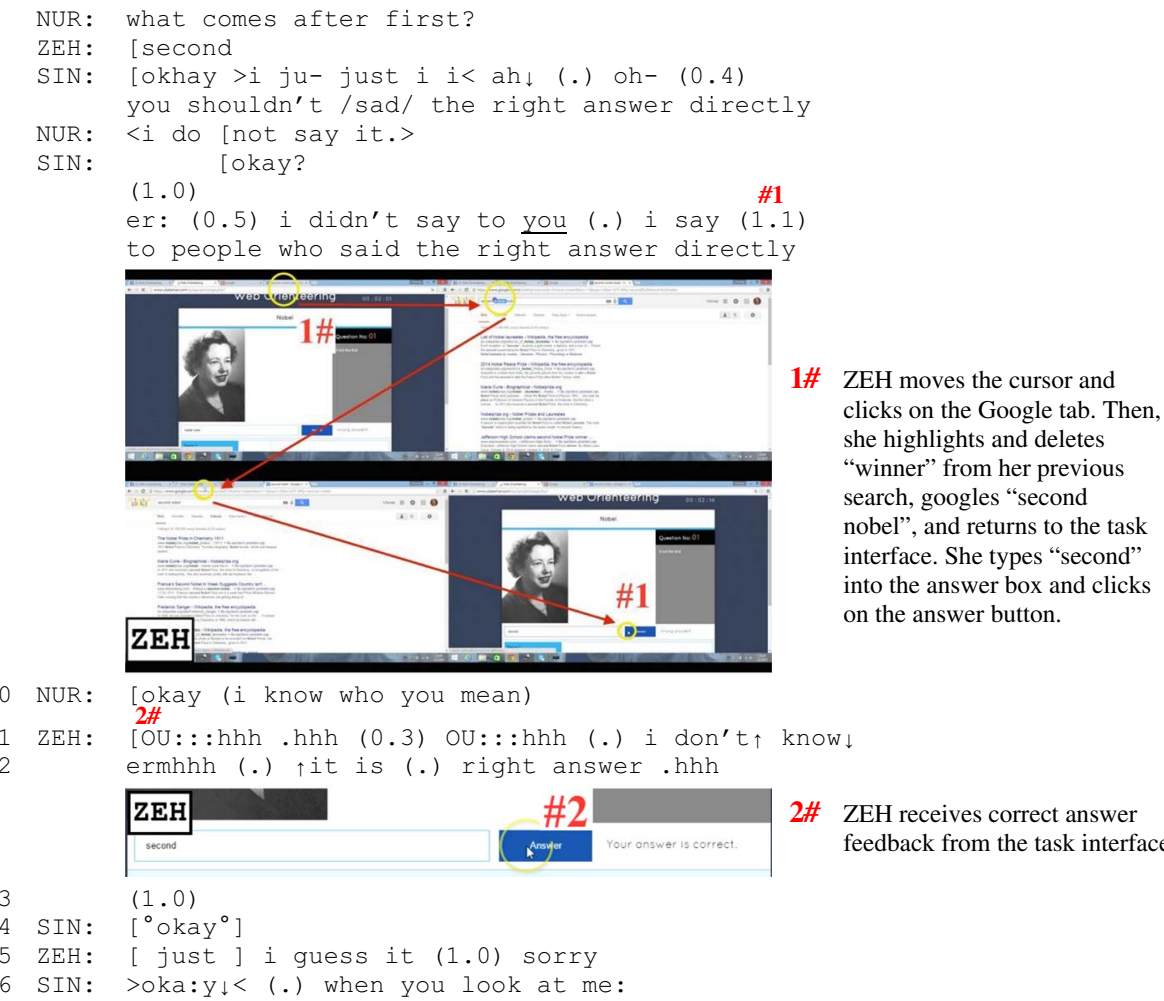

In line 1, NUR provides a clue in order to elicit the correct answer from her teammates. ZEH responds to NUR's clue in line 2 giving the correct answer ( [ second), which is an obvious breach of the task rule do not tell the correct answer. This breach overlaps with SIN's turn initial [okhay in line 3 that actually aims to initiate the closing of the sequence prior to this extract, but it is cancelled and marked with cut-offs and repetitive first-person pronouns uttered with faster pace and surprise markers (ah $\downarrow$ (.) oh-) (Lindström, 1994). After a short silence in line 4, SIN undertakes a policing action and makes it explicit for the co-participants that there is a trouble in the ongoing talk (you shouldn't/sad/the right answer directly). In line 5, NUR provides an account with slower pace (i do [not say it.), which overlaps with SIN's understanding check ( [ okay?) in line 6. NUR takes the blame, as is evident from her account, although she is not the one who breached the task rule. After 1.0 second of silence in line 7, SIN starts a new turn with a hesitation marker (er:) and repairs a misunderstanding by the addressee of the rule policing. She formulates the repair explicitly without using any mitigations or hedges, which is marked with the emphasis ( $\underline{\text { you }}$ ) and the use of a direct reference (to people) in lines 8 and 9 . This action also reinforces the impact of the policing that SIN has initiated and that has not been resolved yet due to the lack of the participants' acceptance of the breach.

The silence in line 8 is also the point that ZEH completes her on-screen activity (\#1), during which she conducts a Google search, returns to the task interface, and submits the correct answer; however, she has not received any feedback yet. It also shows that ZEH 
might not be aware of the fact that the policing action is addressed to her because she does not know that second is the correct answer yet. In line 10, NUR accepts SIN's explanation ( [okay (i know who you mean)). This line overlaps with line 11, which starts with ZEH's noticing of the correct answer due to the feedback from the task interface (\#2). ZEH's talk is marked with loud, stretched, and repetitive change-of-state tokens (Heritage, 1984) followed by the initiation of an account-giving (i don't $\uparrow$ know $\downarrow$ ermhh (.) $\uparrow$ it is (.) right answer .hhh). She formulates her account as she did not know that her candidate answer was correct in line 11 and 12, which also aligns with her previous on-screen activity, thus drawing on the multilayeredness of action co-construction in the setting (Balaman \& Sert, 2017a; Goodwin, 2013). After 1.0 second of silence, SIN accepts her account with soft voice in an overlapping fashion with ZEH's ongoing account-giving in line 15. ZEH continues her account by framing her breach as a guess and ends the turn with an apology (sorry). This apology receives another acceptance from SIN in line 16 that is uttered with faster pace and falling intonation in the word-final position and indicates a transition to the next question (>oka:y $\downarrow<$ ). In the meantime, the task interface takes the participants to the next question.

The extract shows the negotiation of do not tell the correct answer task rule. It can be claimed that the policing sequences and the goal orientation of the task are intricately connected, while the negotiation of the rules and the search for the correct answers function as multiple layers of this task-oriented interaction (Goodwin, 2013). It should also be noted that ZEH was the participant whose actions were the object of policing in the extract. In the following extract, YEL receives similar attention from the co-participants in Team 2. Extract 2 comes from Team 2's first encounter with the task (see Figure 1 in Section 3) at the first minute of the first week.

Extract 2. Other-initiated other (language) policing; Team 2 Week 1

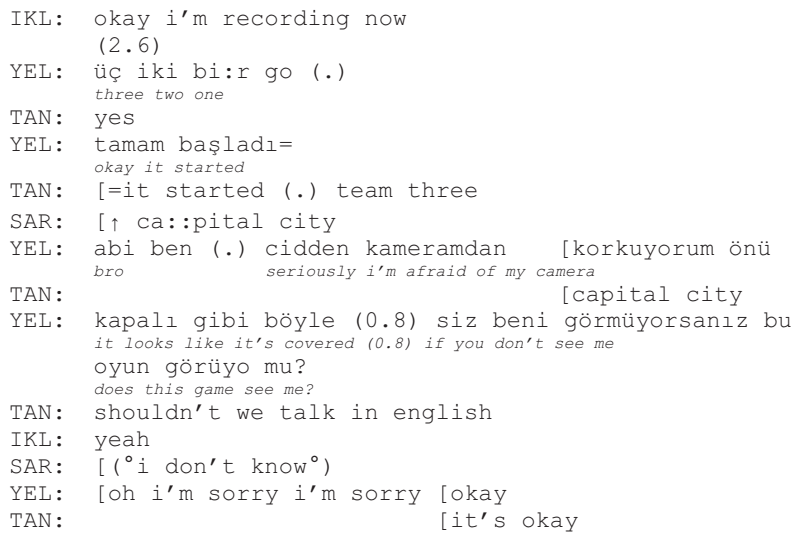

In line 1, IKL marks the pre-beginning of the task, which is followed by YEL's countdown. The countdown turn (line 3) of YEL is an instance of code-switching, as it starts with numbers in Turkish and the turn is closed with an initiation marker (go) in English. This bilingual turn construction is responded to with a compliance token (yes) in English by TAN in line 4, and is followed by an L1 utterance (tamam bașladı = okay it started). In line 6, TAN also flags the initiation of the task in an overlapping fashion with SAR in line 7 and closes the task initiation sequence. The bilingual nature of this interaction thus far has not 
been sanctioned by the participants, as from line 3 to line 6 there is a pre-task sequence that aims to launch the task. Yet, each participant has constructed their turns using L1, L2, and/or bilingual formats to enact the actions that they have initiated. That is, IKL and TAN display a preference for L2-only turns, and YEL for both L1 and bilingual turn construction.

In line 7, SAR reads the on-screen clue aloud ([ $\uparrow c a:$ : pital city) and marks for the other team members the initiation of the task in overlap with TAN in line 6. These two turns precede YEL's long turn in L1 (from lines 8 to 11). Starting her turn with a solidaritymarking address turn $(a b i=b r o)$, YEL complains about her webcam and questions whether the computer and the task interface are able to process her gaming practices, thus producing a multi-unit turn in Turkish. The multi-unit turn also overlaps with TAN's orientation to the task interface with a reference to the clue in line 9. However, rather than orienting to YEL's complaint and confirmation request, TAN undertakes an other-initiated other-repair in line 12 (shouldn't we talk in english), an act of language policing. This action, which is designed to clarify the rules of the task, is at the same time an implicit disapproval of the use of Turkish, and it is aligned with by another participant, IKL. IKL in line 13 produces a compliance token, while SAR marks his uncertainty in line 14 in overlap with YEL's apology. In line 15, the producer of the L1 utterance, YEL, apologizes twice (oh i'm sorry i'm sorry) for her use of Turkish with a change-of-state token in turn-initial position. This token possibly flags understanding or remembering and represents an orientation to the target language only rule that has just been co-constructed. The turn is produced in L2 and therefore displays a compliance with the rules and expectations of the task as negotiated in situ and achieved through an online, collaborative decision-making process. Lastly, YEL ends the turn with an okay in overlap with the immediately following turn. In line 16, TAN, who initiated the policing sequence, minimizes the face-threatening effect and shows acceptance to the apologies (it's okay) and closes the other-policing sequence. This analysis shows that the participants may negotiate and coconstruct language rules through other-policing within other-initiated other-repair sequences as explicated in the extract with the co-construction of the target language only rule, although it was not instructed in the introduction meeting.

The analyses of all cases in the corpus revealed that other-policing sequences evolve into self-policing over time. The two extracts exhibited here have exemplified the ways and sequential formats of negotiation and co-construction of rules through rule and language policing. In the following section, we illustrate how these negotiated and co-constructed rules are oriented to by the participants whose actions were policed in the previous extracts (i.e. ZEH and YEL) in self-policing sequences.

\subsection{Orientations to negotiated and co-constructed task rules}

A longitudinal tracking of the task-oriented interactions reveals that the number of otherpolicing sequences decreases over time. Gradually, and in line with this decrease, rule orientations within self-policing sequences start emerging after enough time is spent on the tasks, which is as short as 50 minutes for a group (Team 2 - Extract 4 ) and 8 weeks for another group (Team 1 - Extract 3). Such orientations are intertwined with the actions of rule and language policing once again. Taking a longitudinal, developmental perspective, it can be argued that these orientations evidence learning in an L2 context as made observable by the participants' shift into self-repairs across time (Martin, 2004, 2009; Martin \& Sahlström, 2010). The following two extracts demonstrate how the participants orient to 


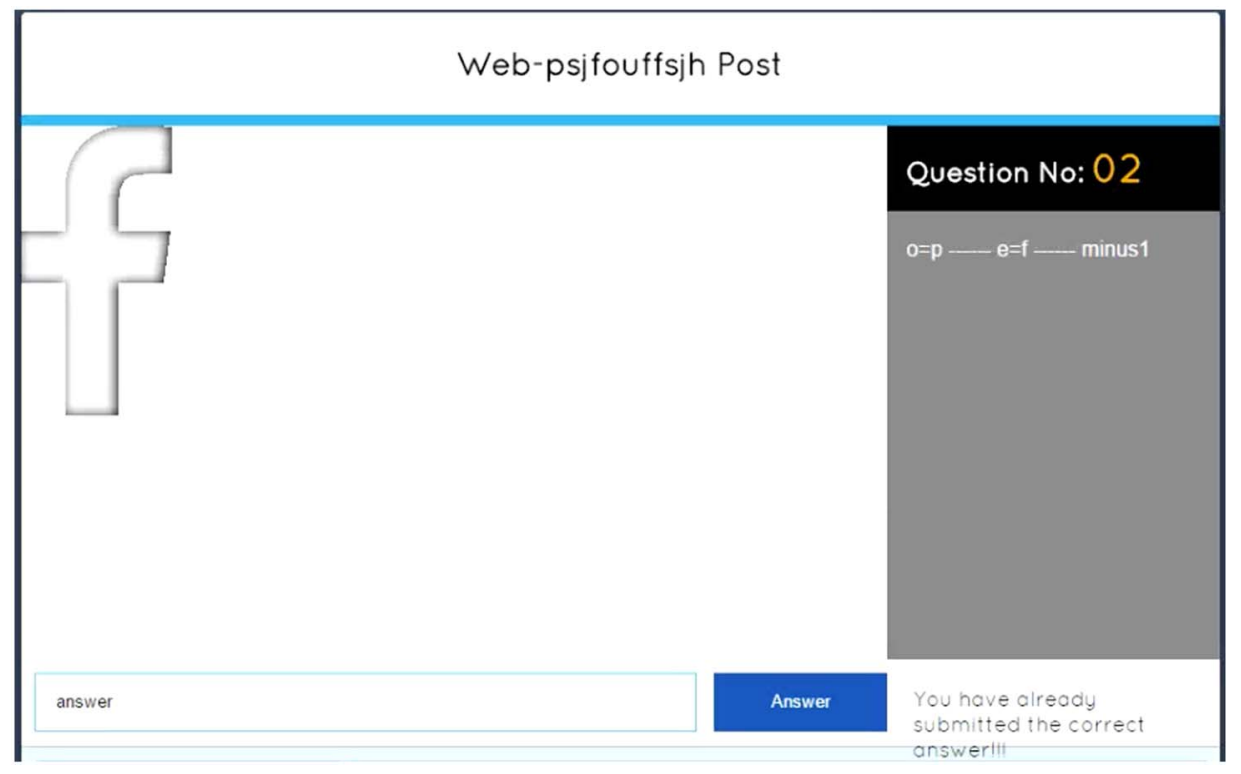

Figure 3. Screenshot of the task interface in Extract 3

previously negotiated task (see Extract 3) and co-constructed language rules (see Extract 4) within self-initiated self-repair sequences.

Extract 3 that follows displays how a participant from Team 1, ZEH, who became the target of rule policing in Extract 1, orients to a task rule by repairing her own breach in the same turn (i.e. self-initiated self-repair). She performs this by omitting the correct answer in a reformulation. The extract comes from the eighth week of the data collection process and the answer to this question is the word answer, implied with a simple one-letter anagram on the task interface (see Figure 3).

Extract 3. Self-initiated self (rule) policing; Team 1 Week 8

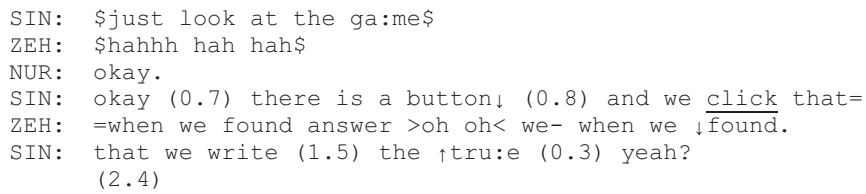

In line 1, SIN provides a clue with a smiley tone and ZEH laughs in response to SIN's turn. In line 3, NUR closes the sequence with an okay and shows receipt to SIN's clue. SIN obtains the floor again and restarts the sequence with an elaboration on her previous instruction in line 1 . This time she stresses the verb ( $\underline{\text { click })}$ to emphasize the action that they always undertake to submit their candidate answers. The end of her turn is latched by $\mathrm{ZEH}$ in line 5 and she enacts a collaborative turn completion (=when we found answer). ZEH's formulation is a breach of the rule because the word answer is actually the correct answer. She notices the breach immediately, marks her noticing with repetitive change-of-state tokens $(>\mathrm{oh} \circ \mathrm{h}<$ ), and starts a reformulation that does not include the answer. This turn constructional unit (we- when we $\downarrow_{\text {found }}$ ) occurs in utterance-final position and is delivered with a falling intonation to signal the end of the turn ( $\downarrow$ found.), 
which actually is a syntactic rule violation (i.e. a transitive verb not being completed by an object). This self-repair is an instance of self-policing that helps ZEH avoid a possible sanction by omitting the word answer in her reformulation. This action shows an explicit orientation to do not tell the correct answer rule. Her avoidance of this transgression with her self-repair is an interactional achievement in that she manages to resolve it without the attention of the other participants. This preference for maintaining the progressivity of interaction eventually takes the team to task completion. The extract continues with SIN's completion of her own turn (that we write). It is also remarkable that she does not orient to the breach of the task rule this time, possibly because ZEH has just taken care of it herself. Finally, SIN refers to the answer box with her clue in line 6 once again, and the extract ends with 2.4 seconds of silence.

Extract 4 that follows demonstrates another instance of language policing occurring within a self-initiated self-repair sequence. The data come from Team 2's discussion on the visual clue of the third question in the first week (see Figure 4), and the participant who is performing the self-policing sequence is YEL, who actually used Turkish (L1) in Extract 2, which triggered an other-policing sequence 50 minutes before the following extract. Prior to the extract, YEL conducts an image search and finds a wiki page on the first photo (visual clue) in history with a recognizable human form (textual clue) taken by Louis Daguerre.

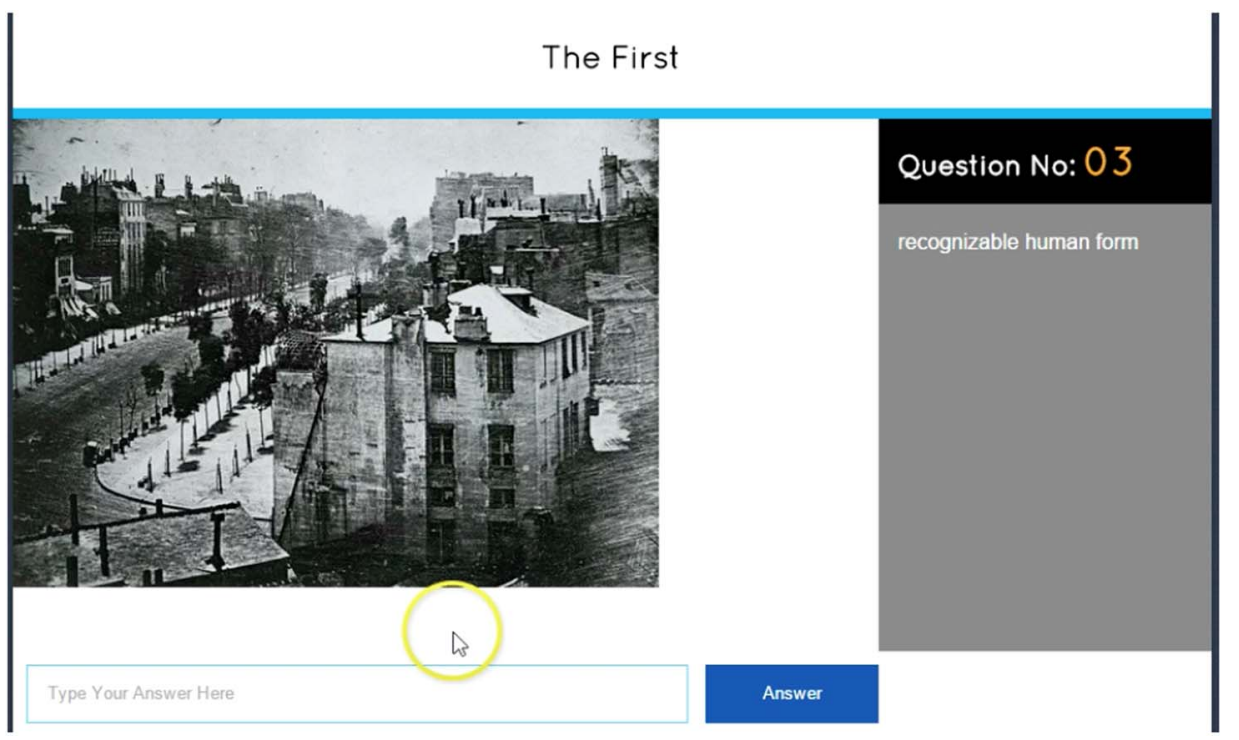

Figure 4. Screenshot of the task interface in Extract 4

Extract 4. Self-initiated self (language) policing; Team 2 Week 1
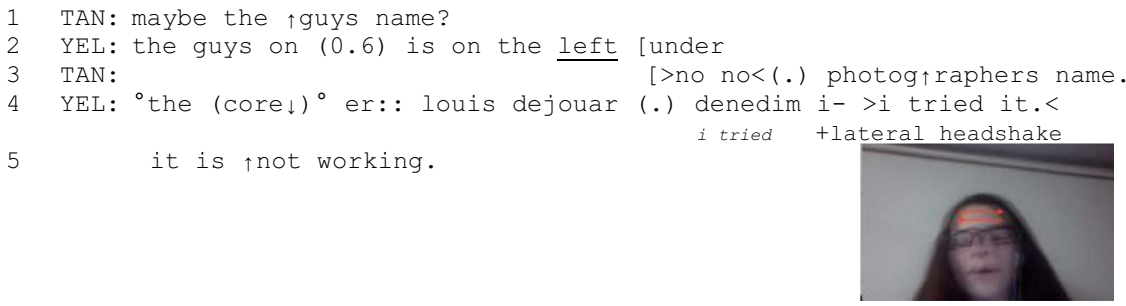
In line 1, TAN, having found the same wiki page, suggests the photographer's name as a candidate answer. In the following line, produced with a restart, YEL states that the textual clue recognizable human form refers to the visible human figure in the photo, and she describes the specific location and identification of the human figure (the guys on $(0.6)$ is on the left (under). The final word in her utterance overlaps with TAN's turn in line 3 in which he initially produces a disagreement marker with faster pace ( $>$ no no $<$ ). After a micro-pause, he deploys an other-initiated other-repair to resolve the misunderstanding on the identity of the person (photog $\uparrow$ raphers name.) whom he referred to in line 1 . His repair is responded to immediately by YEL in line 4 after the completion of her utterance back in line 2 as she provides the name of the photographer. This response is followed by a micro-pause and a word in Turkish (denedim=i tried), which is used to report to TAN (and possibly to the other participants) that she has already tried this candidate item to check whether it is the correct answer. In what follows in the same turn is a self-policing performed through a selfinitiated self-repair (i- >i tried it.). YEL replaces the Turkish word (denedim) with its English equivalent (i- >i tried it), thus performing self-initiated language policing. It should also be noted that her self-repair in English is also suprasegmentally marked as she changes the pace of her talk. Furthermore, there is a multimodal orientation in that she shakes her head (see the lateral arrows in the frame grab) as she undertakes self-policing. The extract ends with her completion of the turn in which she reports her candidate answer. YEL's self-policing has helped her avoid a projected other-policing by TAN that would delay the task accomplishment, and she therefore maintains the progressivity of interaction by deploying an interactional resource (Balaman \& Sert, 2017b) that orients to a task rule (i.e., target language only) that they have co-constructed as a team.

To sum up, this section presented the emergence of NoM within policing sequences through the participants' negotiation and co-construction of language and task rules (Extracts 1-2) as well as their orientations to the negotiated and co-constructed rules (Extract 3-4). The implications of these findings are discussed in the following section.

\section{Discussion and conclusion}

The present study has illustrated how L2 learners (1) negotiate and co-construct the rules of an online L2 task in and through multiparty interactions and (2) how these rules are made relevant and are oriented to within repair sequences. Our analyses in the previous section have shown that the rules emerge and are talked into being in the form of other-initiated other-repairs and self-initiated self-repairs. We have documented that the social action of (a) policing and (b) language and task rules function concurrently through an interactional continuum that starts with the overuse of other rule and language policing and then evolves into self-policing, an indication of development and learning (Martin, 2004, 2009; Martin \& Sahlström, 2010).

There was only one predetermined task rule that was declared prior to task process; however, the findings have shown that in addition to bringing this single rule (do not tell the correct answer) into the interaction, the participants have also co-constructed the target language only rule when there were possible divergences from the rules. Their orientations across different times in the process have brought evidence to the role of NoM in L2 talk-ininteraction in that the participants in this study have learned, applied, oriented to, and 
aligned with the sequentially negotiated language and task rules. Therefore, a processoriented developmental tracking has explicated that the participants have developed interactional competencies to deal with possible breakdowns and maintain progressivity in order to enact collaborative task accomplishment. The interactional change in both short- and long-term repair practices align with previous findings (Martin 2004, 2009; Martin \& Sahlström, 2010) and contribute to the growing body of literature on L2 interactional competence (Hall \& Pekarek Doehler, 2011; Pekarek Doehler \& Berger, 2016; Pekarek Doehler \& Pochon-Berger, 2015; Watanabe, 2017). The change across time has brought concrete evidence to bear on how NoM can be a catalyst for learning in L2 (i.e. learning of task rules in our case) as explicated through the evolution from other-repairs to self-repairs. Language policing also becomes a site for ensuring increased L2 use, through which participants avoid using linguistic resources in their L1.

The analysis carried out supports the conceptualization of NoM around repair as a social-interactional conversation analytic practice rather than a coding category. It also exemplified the enactment of repair through policing (Amir \& Musk, 2013). The findings contribute to the framing of NoM as an interactional phenomenon rather than as a solely cognitive notion described in the previous NoM literature (Jepson, 2005; Long, 1996; Nakahama et al., 2001; Varonis \& Gass, 1985). NoM in repair sequences have been deployed for the purpose of collaborative meaning making in order to build intersubjectivity at turns-at-talk. To this end, this study has presented an alternative to the Varonis and Gass model (1985) (e.g. Fernández-García \& Martínez-Arbelaiz, 2002; Smith, 2003; van der Zwaard \& Bannink, 2014; Yanguas, 2010) by using CA.

The results also reveal another emergent phenomenon in terms of the impact of task design on the interactions. It has been evident in the analysis that emergent information gap tasks provided through the task interface have the potential to facilitate an effective combination of TBLT and CALL. In alignment with González-Lloret and Ortega's (2014) five-step task features model, our task (1) puts the primary focus on meaning; (2) promotes oral communication for task completion; (3) is based on learner-learner interaction without the presence of a teacher or moderator; (4) facilitates group work and discussion that is occasionally reflected in the real world and achieved through (5) the collaborative task engagement of the participants. All of these features contribute to the emerging understanding of task-induced development by exemplifying how the design of an online task environment can potentially elicit longitudinal learning outcomes (Balaman, 2016; Balaman \& Sert, 2017b).

This research establishes links between technology-mediated TBLT and socialinteractionist SLA primarily through CA, which has brought longitudinal and developmental evidence into the occurrence of NoM in online L2 task-oriented interactions. We therefore suggest that NoM, as an essential constituent of cognitivist/interactionist SLA (Doughty \& Long, 2003; Long, 1996; Varonis \& Gass, 1985), is indeed a catalyst for learning as revealed by the participants' developed interactional competencies in this L2 context (Balaman, 2016; Balaman \& Sert, 2017b). Further research may broaden our conceptualization through investigations of form-focused negotiation sequences in the long run, which was not addressed in the present study. Finally, the approach to learning adopted in this paper also reflects the role of multimodality that surrounds online interactions. It contributes to an understanding of the co-construction of knowledge based on the multitude of semiotic, interactional, and epistemic resources (Goodwin, 2013) that the participants deploy to complete tasks by resorting to their on-screen activities and bringing them into 
interaction (Balaman \& Sert, 2017a). The emergent use of on-screen tools in order to accomplish online L2 tasks is another research site to which this study can contribute (Musk, 2016; Piirainen-Marsh \& Tainio, 2014). Although the use of screen recordings and their integration into the analysis have been a clear strength, further research can also incorporate eye-tracking methodology to describe noticing processes of learners. Therefore, a combination of CA and eye tracking has lots to offer for the development of technologymediated TBLT.

\section{Acknowledgements}

This research is based on a $\mathrm{PhD}$ thesis submitted to the Institute of Educational Sciences, Hacettepe University (Balaman, 2016). We would like to thank Numa Markee and Chris Jenks for their invaluable feedback on earlier versions of this paper.

\section{References}

Amir, A. (2013) Self-policing in the English as a foreign language classroom. Novitas-ROYAL (Research on Youth and Language), 7(2): 84-105.

Amir, A. and Musk, N. (2013) Language policing: Micro-level language policy-in-process in the foreign language classroom. Classroom Discourse, 4(2): 151-167. https://doi.org/10.1080/19463014.2013. 783500

Auer, P. (1984) Bilingual conversation. Amsterdam: John Benjamins. https://doi.org/10.1075/pb.v.8

Balaman, U. (2015) A conversation analytic investigation into the impact of task design on the emergence of information gaps. In Colpaert, J., Aerts, A., Oberhofer, M. \& Plana, M. G. C. (eds.), Proceedings of 17th International CALL Conference: Task Design \& CALL. Tarragona, Spain: Universitat Rovira i Virgili, 95-104.

Balaman, U. (2016) A conversation analytic study on the development of interactional competence in English in an online task-oriented environment. Hacettepe University, Turkey, unpublished PhD.

Balaman, U. and Sert, O. (2017a) The coordination of online L2 interaction and orientations to task interface for epistemic progression. Journal of Pragmatics, 115: 115-129. https://doi.org/10.1016/ j.pragma.2017.01.015

Balaman, U. and Sert, O. (2017b) Development of L2 interactional resources for online collaborative task accomplishment. Computer Assisted Language Learning, 30(7): 601-630. https://doi.org/ 10.1080/09588221.2017.1334667

Belz, J. A. \& Thorne, S. L. (eds.) (2006) Internet-mediated intercultural foreign language education. Boston: Thomson, Heinle.

Bonacina-Pugh, F. (2012) Researching 'practiced language policies': Insights from conversation analysis. Language Policy, 11(3): 213-234. https://doi.org/10.1007/s10993-012-9243-x

Bower, J. and Kawaguchi, S. (2011) Negotiation of meaning and corrective feedback in Japanese/ English eTandem. Language Learning \& Technology, 15(1): 41-71.

Doughty, C. J. and Long, M. (2003) Optimal psycholinguistic environments for distance foreign language learning. Language Learning \& Technology, 7(3): 50-80.

Doughty, C. J. and Pica, T. (1986) "Information gap" tasks: Do they facilitate second language acquisition? TESOL Quarterly, 20(2): 305-325. https://doi.org/10.2307/3586546

Fernández-García, M. and Martínez-Arbelaiz, A. (2002) Negotiation of meaning in nonnative speaker-nonnative speaker synchronous discussions. CALICO Journal, 19(2): 279-294.

Firth, A. and Wagner, J. (1997) On discourse, communication, and (some) fundamental concepts in SLA research. The Modern Language Journal, 81(3): 285-300. https://doi.org/10.1111/j.15404781.1997.tb05480.x 
Foster, P. and Ohta, A. S. (2005) Negotiation for meaning and peer assistance in second language classrooms. Applied Linguistics, 26(3): 402-430. https://doi.org/10.1093/applin/ami014

Gafaranga, J. (2000) Medium repair vs. other-language repair: Telling the medium of a bilingual conversation. International Journal of Bilingualism, 4(3): 327-350. https://doi.org/10.1177/136 70069000040030301

Gafaranga, J. (2010) Medium request: Talking language shift into being. Language in Society, 39(2): 241-270. https://doi.org/10.1017/S0047404510000047

González-Lloret, M. (2015) Conversation analysis in computer-assisted language learning. CALICO Journal, 32(3): 569-594. https://doi.org/10.1558/cj.v32i3.27568

González-Lloret, M. and Ortega, L. (2014) Towards technology-mediated TBLT: An introduction. In González-Lloret, M. \& Ortega, L. (eds.), Technology-mediated TBLT: Researching technology and tasks. Amsterdam: John Benjamins, 1-21.

Goodwin, C. (2013) The co-operative, transformative organization of human action and knowledge. Journal of Pragmatics, 46(1): 8-23. https://doi.org/10.1016/j.pragma.2012.09.003

Hall, J. K. and Pekarek Doehler, S. (2011) L2 interactional competence and development. In Hall, J. K., Hellermann, J. \& Pekarek Doehler, S. (eds.), L2 interactional competence and development. Bristol, UK: Multilingual Matters, 1-15.

Hauser, E. (2005) Coding 'corrective recasts': The maintenance of meaning and more fundamental problems. Applied Linguistics, 26(3): 293-316. https://doi.org/10.1093/applin/ami010

Hazel, S. (2015) Identities at odds: Embedded and implicit language policing in the internationalized workplace. Language and Intercultural Communication, 15(1): 141-160. https://doi.org/10.1080/ 14708477.2014.985311

Hellermann, J. (2008) Social actions for classroom language learning. Clevedon, UK: Multilingual Matters.

Hellermann, J. and Pekarek Doehler, S. (2010) On the contingent nature of language-learning tasks. Classroom Discourse, 1(1): 25-45. https://doi.org/10.1080/19463011003750657

Heritage, J. (1984) A change-of state token and aspects of its sequential placement. In Maxwell Atkinson, J. \& Heritage, J. (eds.), Structure of social action: Studies in conversation analysis. Cambridge: Cambridge University Press, 299-345.

Jakonen, T. and Morton, T. (2015) Epistemic search sequences in peer interaction in a contentbased language classroom. Applied Linguistics, 36(1): 73-94. https://doi.org/10.1093/applin/ amt031

Jefferson, G. (2004) Glossary of transcript symbols with an introduction. In Lerner, G. H. (ed.), Conversation analysis: Studies from the first generation. Amsterdam: John Benjamins, 13-34. https://doi.org/10.1075/pbns.125.02jef

Jenks, C. J. (2014) Social interaction in second language chat rooms. Edinburgh: Edinburgh University Press.

Jepson, K. (2005) Conversations - and negotiated interaction - in text and voice chat rooms. Language Learning \& Technology, 9(3): 79-98.

Kasper, G. and Wagner, J. (2011) A conversation-analytic approach to second language acquisition. In Atkinson, D. (ed.), Alternative approaches to second language acquisition. Abingdon, UK: Routledge, 117-142.

Kern, R. G. (1995) Restructuring classroom interaction with networked computers: Effects on quantity and characteristics of language production. The Modern Language Journal, 79(4): 457-476. https:// doi.org/10.1111/j.1540-4781.1995.tb05445.x

Kitade, K. (2000) L2 learners' discourse and SLA theories in CMC: Collaborative interaction in internet chat. Computer Assisted Language Learning, 13(2): 143-166. https://doi.org/10.1076/ 0958-8221(200004)13:2;1-D;FT143

Kitzinger, C. (2013) Repair. In Sidnell, J. \& Stivers, T. (eds.), The handbook of conversation analysis. Chichester, UK: Blackwell, 229-256. 
Lee, L. (2001) Online interaction: Negotiation of meaning and strategies used among learners of Spanish. ReCALL, 13(2): 232-244. https://doi.org/10.1017/S0958344001000829a

Lee, Y.-A. (2013) Descriptions of second language interaction: Toward descriptive adequacy. The Modern Language Journal, 97(4): 853-868. https://doi.org/10.1111/j.1540-4781.2013. 12041.x

Lindström, A. (1994) Identification and recognition in Swedish telephone conversation openings. Language in Society, 23(2): 231-252. https://doi.org/10.1017/S004740450001784X

Long, M. H. (1996) The role of the linguistic environment in second language acquisition. In Ritchie, W. \& Bhatia, T. (eds.), Handbook of second language acquisition. San Diego, CA: Academic Press, 413-468. https://doi.org/10.1016/B978-012589042-7/50015-3

Markee, N. and Kasper, G. (2004) Classroom talks: An introduction. The Modern Language Journal, 88(4): 491-500. https://doi.org/10.1111/j.0026-7902.2004.t01-14-.x

Markee, N. and Kunitz, S. (2013) Doing planning and task performance in second language acquisition: An ethnomethodological respecification. Language Learning, 63(4): 629-664. https://doi.org/10.1111/lang.12019

Martin, C. (2004) From other to self: Learning as interactional change. Uppsala, Sweden: Acta Universitatis Uppsaliensis.

Martin, C. (2009) Relevance of situational context in studying learning as changing participation. Scandinavian Journal of Educational Research, 53(2): 133-149. https://doi.org/ $10.1080 / 00313830902757568$

Martin, C. and Sahlström, F. (2010) Learning as longitudinal interactional change: From other-repair to self-repair in physiotherapy treatment. Discourse Processes, 47(8): 668-697. https://doi.org/ $10.1080 / 01638531003628965$

Meunier, L. (1998) Personality and motivational factors in electronic networking. In Muyskens, J. A. (ed.), New ways of learning and teaching: Focus on technology and foreign language education. Boston: Heinle, 63-126.

Mondada, L. and Pekarek Doehler, S. (2004) Second language acquisition as situated practice: Task accomplishment in the French second language classroom. Modern Language Journal, 88(4): 501-518. https://doi.org/10.1111/j.0026-7902.2004.t01-15-.x

Mori, J. (2004) Pursuit of understanding: Rethinking 'negotiation of meaning' in view of projected action. In Gardner, R. \& Wagner, J. (eds.), Second language conversations. London: Continuum, 157-177.

Musk, N. (2016) Correcting spellings in second language learners' computer-assisted collaborative writing. Classroom Discourse, 7(1): 36-57. https://doi.org/10.1080/19463014.2015.1095106

Nakahama, Y., Tyler, A. and Van Lier, L. (2001) Negotiation of meaning in conversational and information gap activities: A comparative discourse analysis. TESOL Quarterly, 35(3): 377-405. https://doi.org/10.2307/3588028

Pekarek Doehler, S. and Berger, E. (2016) L2 interactional competence as increased ability for context-sensitive conduct: A longitudinal study of story-openings. Applied Linguistics. https://doi. org/10.1093/applin/amw021

Pekarek Doehler, S. and Pochon-Berger, E. (2015) The development of L2 interactional competence: Evidence from turn-taking organization, sequence organization, repair organization and preference organization. In Cadierno, T. \& Eskildsen, S. W. (eds.), Usage-based perspectives on second language learning. Berlin: De Gruyter, 233-268. https://doi.org/10.1515/9783110378528-012

Pellettieri, J. (2000) Negotiation in cyberspace: The role of chatting in the development of grammatical competence. In Warschauer, M. \& Kern, R. (eds.), Network-based language teaching: Concepts and practice. Cambridge: Cambridge University Press, 59-86. doi: https://doi.org/10.1017/ CBO9781139524735.006.

Piirainen-Marsh, A. and Tainio, L. (2014) Asymmetries of knowledge and epistemic change in social gaming interaction. The Modern Language Journal, 98(4): 1022-1038. https://doi.org/10.1111/ modl. 12153 
Salaberry, M. R. (2000) L2 morphosyntactic development in text-based computer-mediated communication. Computer Assisted Language Learning, 13(1): 5-27. https://doi.org/10.1076/09588221(200002)13:1;1-K;FT005

Sacks, H., Schegloff, E. A. and Jefferson, G. (1974) A simplest systematics for the organization of turn-taking for conversation. Language, 50(4): 696-735. https://doi.org/10.1353/lan.1974.0010

Schegloff, E. A., Jefferson, G. and Sacks, H. (1977) The preference for self-correction in the organization of repair in conversation. Language, 53(2): 361-382. https://doi.org/10.1353/ lan.1977.0041

Seedhouse, P. (2005) "Task" as research construct. Language Learning, 55(3): 533-570. https://doi. org/10.1111/j.0023-8333.2005.00314.x

Sert, O. (2015) Social interaction and L2 classroom discourse. Edinburgh: Edinburgh University Press.

Shekary, M. and Tahririan, M. H. (2006) Negotiation of meaning and noticing in text-based online chat. The Modern Language Journal, 90(4): 557-573. https://doi.org/10.1111/j.1540-4781. 2006.00504.x

Sidnell, J. (2010) Conversation analysis: An introduction. Chichester, UK: John Wiley \& Sons.

Sidnell, J. \& Stivers, T. (eds.) (2013) The handbook of conversation analysis. Chichester, UK: Blackwell.

Smith, B. (2003) Computer-mediated negotiated interaction: An expanded model. The Modern Language Journal, 87(1): 38-57. https://doi.org/10.1111/1540-4781.00177

Smith, B. (2004) Computer-mediated negotiated interaction and lexical acquisition. Studies in Second Language Acquisition, 26(3): 365-398. https://doi.org/10.1017/S027226310426301X

Smith, B. (2005) The relationship between negotiated interaction, learner uptake, and lexical acquisition in task-based computer-mediated communication. TESOL Quarterly, 39(1): 33-58. https:// doi.org/10.2307/3588451

Smith, B. (2009) Task-based learning in the computer-mediated communicative ESL/EFL classroom. CALL-EJ Online, 11(1). http://callej.org/journal/11-1/smith.html

Sotillo, S. M. (2000) Discourse functions and syntactic complexity in synchronous and asynchronous communication. Language Learning \& Technology, 4(1): 77-110.

ten Have, P. (2007) Doing conversation analysis: A practical guide (2nd ed.). London: Sage. https:// doi.org/10.4135/9781849208895

Tudini, V. (2010) Online second language acquisition: Conversation analysis of online chat. London: Continuum.

Tudini, V. and Liddicoat, A. J. (2017) Computer-mediated communication and conversation analysis. In Thorne, S. L. \& May, S. (eds.), Language, education and technology (3rd ed.). Springer International, 1-12. https://doi.org/10.1007/978-3-319-02237-6_32

van der Zwaard, R. and Bannink, A. (2014) Video call or chat? Negotiation of meaning and issues of face in telecollaboration. System, 44: 137-148. https://doi.org/10.1016/j.system.2014.03.007

van der Zwaard, R. and Bannink, A. (2016) Nonoccurrence of negotiation of meaning in task-based synchronous computer-mediated communication. The Modern Language Journal, 100(3): 625640. https://doi.org/10.1111/modl.12341

Varonis, E. M. and Gass, S. (1985) Non-native/non-native conversations: A model for negotiation of meaning. Applied Linguistics, 6(1): 71-90. https://doi.org/10.1093/applin/6.1.71

Wang, Y. (2006) Negotiation of meaning in desktop videoconferencing-supported distance language learning. ReCALL, 18(1): 122-145. https://doi.org/10.1017/S0958344006000814

Watanabe, A. (2017) Developing L2 interactional competence: Increasing participation through selfselection in post-expansion sequences. Classroom Discourse, 8(3): 271-293. https://doi.org/ 10.1080/19463014.2017.1354310

Yanguas, Í. (2010) Oral computer-mediated interaction between L2 learners: It's about time! Language Learning \& Technology, 14(3): 72-93. 
Yanguas, Í. (2012) Task-based oral computer-mediated communication and L2 vocabulary acquisition. CALICO Journal, 29(3): 507-531. https://doi.org/10.11139/cj.29.3.507-531

Yüksel, D. and İnan, B. (2014) The effects of communication mode on negotiation of meaning and its noticing. ReCALL, 26(3): 333-354. https://doi.org/10.1017/S0958344014000147

Zheng, D., Young, M. F., Wagner, M. M. and Brewer, R. A. (2009) Negotiation for action: English language learning in game-based virtual worlds. The Modern Language Journal, 93(4): 489-511. https://doi.org/10.1111/j.1540-4781.2009.00927.x

\title{
Appendix
}

\section{Transcription conventions}

\begin{tabular}{|c|c|}
\hline I\# & $\begin{array}{l}\text { Onset point of the on-screen activity surrounding the talk that is marked along with the } \\
\text { lines of the transcript }\end{array}$ \\
\hline \#1 & $\begin{array}{l}\text { Offset point of the on-screen activity surrounding the talk that is marked along with the } \\
\text { lines of the transcript }\end{array}$ \\
\hline Illustrations & Current web page(s) of the participants who perform the on-screen activities \\
\hline Circles & Points on the screen that the participants either click or hold the cursor still \\
\hline Arrow & Direction of the cursor movements within the on-screen activity illustrations \\
\hline Descriptions & $\begin{array}{l}\text { Unanalytical descriptions of the illustrated on-screen activities that are provided } \\
\text { following the offset point of the on-screen activity }\end{array}$ \\
\hline
\end{tabular}

Note. These notations only include our additions to Jeffersonian (Jefferson, 2004) transcription conventions (see Extract 1).

\begin{abstract}
About the authors
Olcay Sert is the editor of Classroom Discourse (Routledge), and is the author of Social Interaction and L2 Classroom Discourse, published by the Edinburgh University Press in 2015. His main research approach is conversation analysis, and his research deals primarily with classroom discourse, L2 interactional competence and L2 teacher education.

Ufuk Balaman is based in the department of English Language Teaching at Hacettepe University, Turkey. He is also the vice-director of Hacettepe University Micro-Analysis Network (HUMAN) Research Centre. His main research interest is conversation analysis for online multiparty task-oriented interaction.
\end{abstract}

